\title{
Modelling of Intrinsic Defects in $\mathrm{CaYAl}_{3} \mathrm{O}_{7}$
}

\author{
G.F. DA C. BiSPO ${ }^{a}$, R.A. JACKSON ${ }^{b}$ AND M.E.G. VALERIO ${ }^{a *}$ \\ ${ }^{a}$ Physics Department, Federal University of Sergipe, 49,100-000 Săo Cristovăo, SE, Brazil \\ ${ }^{b}$ School of Chemical and Physical Sciences, Keele University, Keele, ST5 5BG, Staffordshire, United Kingdom
}

$\mathrm{CaYAl}_{3} \mathrm{O}_{7}$ presents a challenge for computer modelling techniques because of its site-occupancy disorder related to the $\mathrm{Ca} / \mathrm{Y}$ shared site. Supercells were built to reproduce experimental results which have the best agreement and lowest lattice energy. The potential parameters were obtained by empirical fitting, and reproduced the structure to within $1.09 \%$. Results obtained by supercell and the Mott-Littleton methods were compared. Both methods predict oxygen Frenkel defects are likely to be formed.

DOI: 10.12693/APhysPolA.133.781

PACS/topics: 61.43.Bn, 61.72.-y, 34.20.Cf

\section{Introduction}

$\mathrm{CaYAl}_{3} \mathrm{O}_{7}$ (CYAM), as with other Y-containing materials, has been studied as a host for rare earth (RE) ions which can induce interesting luminescent properties, including mechanoluminescence $\left(\mathrm{Ce}^{3+}\right.$ and $\mathrm{Eu}^{2+}$ doping), afterglow $\left(\mathrm{Ce}^{3+}\right.$ doping) and up-conversion fluorescence $\left(\mathrm{Yb}^{3+}\right.$ doping $)[1-4]$. CYAM has also been investigated for applications in white LEDs, sensing of structural damage, volumetric displays, temperature sensors and other applications $[5,6]$.

CYAM belongs to the mellilite family and its crystal structure belongs to the space group $P-42_{1} m$, where the $\mathrm{Ca}$ and $\mathrm{Y}$ ions are randomly distributed at the same site in the lattice with a composition ratio of 1:1 [7]. The site-occupancy disorder related to the $\mathrm{Ca} / \mathrm{Y}$ shared site in CYAM produces naturally different local symmetries around defects and this can be connected to the low local symmetry found in the literature for both divalent and trivalent rare earth ions substitute at this $\mathrm{Ca} / \mathrm{Y}$ shared site $[4,7]$.

Computer modelling based on atomistic potentials and energy minimisation has been used to provide fundamental insights into defects in a wide range of materials [810]. These modelling techniques use interatomic potentials to define interactions in the material, and have the advantage that a relatively large number of atoms/ions can be treated explicitly. However, materials with fractional occupancy, like CYAM, represent a challenge for this technique when defects have to be considered in the modelling strategy. The present work aims to develop a strategy to model intrinsic defects in CYAM to obtain the energetics of the possible defects present in the material.

\section{Methodology}

The methodology used to model the defect in CYAM is based on energy minimisation where the interatomic

\footnotetext{
*corresponding author; e-mail: megvalerio@gmail.com
}

interactions are described using a set of interatomic potentials. This same strategy has been applied successfully in a number of systems [8-10].

The usual way of modelling the defects in a material follows three basic steps. Firstly, the interatomic potential set has to be obtained, either by using previously derived potentials, or by deriving a special set to model the material in focus. The second step is to establish the possible defects in the material and the corresponding mechanisms to be used to compute the energetics of the defects in terms of solid state reactions. The third step is performing the calculations of the defect energies involved in the reactions.

In step two, the mechanisms are normally composed of combinations of vacancies, interstitial and substitutional ions depending on the defect of interest. This is the part that presents the challenge in modelling CYAM because if any defect involves either $\mathrm{Ca}$ or $\mathrm{Y}$ ions there is no way to remove just the $\mathrm{Ca}$ or the $\mathrm{Y}$ since the material itself is described as being composed of $50 \% \mathrm{Ca}$ and $50 \% \mathrm{Y}$ at the same lattice site. This may not present problems for general structural methods, like X-ray diffraction (XRD) or the calculation of lattice energies, but it is not suitable for treating defect modelling calculations.

One possible way of overcoming this problem is to represent the material by a supercell that is constructed based on repetitions of the unit cell of CYAM generated from the crystallographic data. In this supercell there are a number of $\mathrm{Ca} / \mathrm{Y}$ sites that can be occupied either by a $\mathrm{Ca}^{2+}$ or an $\mathrm{Y}^{3+}, 50 \%$ each. However, two important issues arise from this approach. Firstly, what is a suitable size for the supercell, and, secondly, how should the $\mathrm{Ca} / \mathrm{Y}$ sites be filled to mimic the random occupancy actually found in the material? In order to properly deal with both issues, as large as possible a supercell should be constructed, and more than one configuration of the $\mathrm{Ca} / \mathrm{Y}$ sites should be considered. The problem now is that using a very large supercell may make the calculations impossible to run due to computer resource limits, and repeating the calculations for a number of configurations can be very time consuming. 
TABLE I
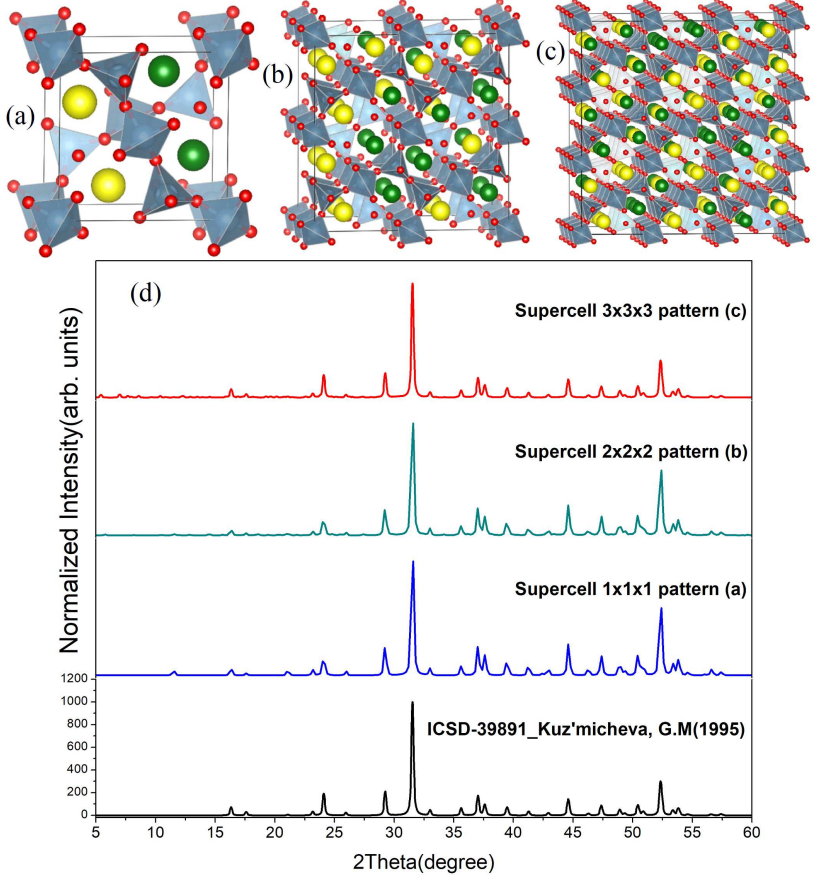

Fig. 1. (a) $1 \times 1 \times 1$ supercell structure viewed along 001 direction, (b) $2 \times 2 \times 2$ supercell structure viewed along 001 direction, (c) $3 \times 3 \times 3$ supercell structure viewed along 001 direction, (d) a comparison between the standard patterns and the calculated ones generated by supercells (a), (b) and (c).

Several supercells were constructed with different numbers of repetitions and distributions. Diffraction patterns were simulated through the GSAS ${ }^{\circledR}$ program [11] and compared with standard diffraction patterns [12]. Figure 1 shows the CYAM basic unit cell plus examples of $2 \times 2 \times 2$ and $3 \times 3 \times 3$ supercells with $\mathrm{Ca} / \mathrm{Y}$ ions randomly distributed. The patterns generated by each cell are also shown. The conditions used to choose the supercells were best agreement between patterns and lowest lattice energy, and this was found for the $3 \times 3 \times 3$ supercell.

The calculations were performed using the computer code GULP [13]. The Buckingham potentials supplemented by electrostatic terms (1) were used to describe the interactions between ions

$$
V_{i j}=A_{i j} \exp \left(\frac{-r_{i j}}{\rho_{i j}}\right)-\frac{C_{i j}}{r_{i j}^{6}}+\frac{q_{i} q_{j}}{r_{i j}}
$$

Here $q_{i}$ and $q_{j}$ are charges on the ions, $r_{i j}$ is their separation, and $A, \rho$ and $C$ are potential parameters. Furthermore, the shell mode was employed to take account of polarisation of the $\mathrm{O}$ ions, while $\mathrm{Ca}, \mathrm{Y}$ and $\mathrm{Al}$ take their formal charges. The potential parameters (Table I) used in this paper were obtained by empirical fitting methods; the agreement between the experimental and calculated lattice parameters is given in Table II.

Having a negative formation enthalpy of CYAM is also considered as a criterion to select the supercell configuration. Table III shows the calculated formation enthalpy for CYAM, according to the reaction below,
Potential parameters used in the CYAM modelling.

\begin{tabular}{cccc}
\hline \hline Interaction & $A[\mathrm{eV}]$ & $\rho[\AA]$ & $C\left[\mathrm{eV} \AA^{6}\right)$ \\
\hline \multicolumn{4}{c}{ Buckingham cut-offs: $10 \AA$} \\
\hline $\mathrm{Y}_{\text {core }}-\mathrm{O}_{\text {shell }}$ & 1345.1 & 0.3372 & 0.0 \\
$\mathrm{Ca}_{\text {core }}-\mathrm{O}_{\text {shell }}$ & 1217.7 & 0.3372 & 0.0 \\
$\mathrm{Al}_{\text {core }}-\mathrm{O}_{\text {shell }}$ & 1396.4 & 0.3006 & 0.0 \\
$\mathrm{O}_{\text {shell }}-\mathrm{O}_{\text {shell }}$ & 22764.0 & 0.1490 & 27.879 \\
\hline \multicolumn{4}{c}{ shell model parameters } \\
\hline spring $\mathrm{O}_{\text {core }}-\mathrm{O}_{\text {shell }}\left[\mathrm{eV} \AA^{-2}\right]$ & 28.0 \\
charge $[|e|]$ & $q_{\text {Ocore }}$ & qOshell \\
& 0.86902 & -2.86902 &
\end{tabular}

TABLE II

Comparison of calculated and experimental structures.

\begin{tabular}{|c|c|c|c|}
\hline \multicolumn{4}{|c|}{$\mathrm{CaYAl}_{3} \mathrm{O}_{7}$ supercell parameters $[\AA]$} \\
\hline & Experimental & Calculated & $\Delta \%$ \\
\hline$a$ & 23.0280 & 22.8451 & 0.79 \\
\hline$b$ & 23.0280 & 22.8429 & 0.80 \\
\hline$c$ & 15.1200 & 15.2844 & 1.09 \\
\hline \multicolumn{4}{|c|}{$\mathrm{Al}_{2} \mathrm{O}_{3}$ parameters } \\
\hline$a=b$ & 4.7657 & 4.7331 & 0.68 \\
\hline$c$ & 13.0100 & 12.6074 & 3.09 \\
\hline \multicolumn{4}{|c|}{$\mathrm{Y}_{2} \mathrm{O}_{3}$ parameters } \\
\hline$a=b=c$ & 10.6017 & 10.5117 & 0.85 \\
\hline \multicolumn{4}{|c|}{$\mathrm{CaO}$ parameters } \\
\hline$a=b=c$ & 4.8152 & 4.8008 & 0.30 \\
\hline
\end{tabular}

using the lattice energies for the precursor oxides (given in the table). Also given in the table are lattice energies for other possible products, which are seen to be negative.

$$
\begin{aligned}
& \mathrm{CaO}+\frac{1}{2} \mathrm{Y}_{2} \mathrm{O}_{3}+\frac{3}{2} \mathrm{Al}_{2} \mathrm{O}_{3} \rightarrow \mathrm{CaYAl}_{3} \mathrm{O}_{7} \\
& \Delta_{\mathrm{CaYAl}_{3} \mathrm{O}_{7}}=E_{\mathrm{CaO}}^{L}+\frac{1}{2} E_{\mathrm{Y}_{2} \mathrm{O}_{3}}^{L}+\frac{3}{2} E_{\mathrm{Al}_{2} \mathrm{O}_{3}}^{L}
\end{aligned}
$$

Calculations of defect energies were performed using two methods: supercells and the Mott-Littleton method $[14,15]$, adapted so that the supercell is used in-

Calculated lattice energies.

TABLE III

\begin{tabular}{cc}
\hline \hline $3 \mathrm{Material}$ & Lattice energy $[\mathrm{eV}]$ \\
$\mathrm{Al}_{2} \mathrm{O}_{3}$ & -161.12 \\
$\mathrm{Y}_{2} \mathrm{O}_{3}$ & -135.42 \\
$\mathrm{CaO}$ & -36.1 \\
$\mathrm{CaAl}_{2} \mathrm{O}_{4}$ & -198.38 \\
$\mathrm{Y}_{4} \mathrm{Al}_{2} \mathrm{O}_{9}$ & -432.32 \\
$\mathrm{Y}_{3} \mathrm{Al}_{5} \mathrm{O}_{12}$ & -606.168 \\
$\mathrm{YAlO}_{3}$ & -148.1 \\
$\mathrm{CaYAl}_{3} \mathrm{O}_{7}$ & -346.31 \\
$\Delta$ H $_{\text {Formation }}\left(\mathrm{CaYAl}_{3} \mathrm{O}_{7}\right)$ & -0.82
\end{tabular}


stead of a basic unit cell. The first method involves: (i) generation of the supercell, (ii) incorporation of defects, and (iii) lattice energy minimisation [14]. This method can provide a concentration of defects beyond the dilute limit. In the second method, the spherical region of the lattice surrounding the defect is treated considering all interactions (region I), while more distant parts are treated using a continuum approach (region II). In order to accommodate the distortions of the lattice induced by the defect, region II is divided into region II(a) and II(b). Each ion displacement in region II(a) is calculated considering an harmonic approximation and region $\mathrm{II}(\mathrm{b})$ is considered to be a dielectric continuum since the influence of the defect is very small [15]. Consistent cut-off radii of $24 \AA$ and $28 \AA$ have been used for regions I and II(a), respectively.

\section{Results and discussion}

A series of calculations were carried out and the formation energies of isolated point defects (vacancies and interstitials) in CYAM were obtained. The formation energy is the energy difference between the defective and perfect lattice; in the supercell method it is the lattice energy obtained after minimisation of the defective and perfect lattice, while in the Mott-Littleton method, the defect formation energy is calculated in the limit of infinite dilution [14].

The intrinsic defect (Frenkel, Schottky and others) reactions have been devised and are listed in Table IV.

TABLE IV

Reaction schemes (defect equations) for intrinsic defects in CYAM.

\begin{tabular}{|c|}
\hline Frenkel defect \\
\hline $\begin{array}{c}\mathrm{Y}_{\mathrm{Y}} \rightarrow \mathrm{Y}_{i}^{\bullet \bullet \bullet}+\mathrm{V}_{\mathrm{Y}}^{\prime \prime \prime} \\
\mathrm{Ca}_{\mathrm{Ca}} \rightarrow \mathrm{Ca}_{i}^{\bullet \bullet}+\mathrm{V}_{\mathrm{Ca}}^{\prime \prime} \\
\mathrm{Al}_{\mathrm{Al}} \rightarrow \mathrm{Al}_{i}^{\bullet \bullet \bullet}+\mathrm{V}_{\mathrm{Al}}^{\prime \prime \prime} \\
\mathrm{O}_{\mathrm{O}} \rightarrow \mathrm{O}_{i}^{\prime \prime}+\mathrm{V}_{\mathrm{O}}^{\bullet \bullet}\end{array}$ \\
\hline Pseudo-Schottky \\
\hline $\begin{array}{c}\mathrm{Ca}_{\mathrm{Ca}}+\mathrm{O}_{\mathrm{O}} \rightarrow \mathrm{V}_{\mathrm{Ca}}^{\prime \prime \prime}+\mathrm{V}_{\mathrm{O}}^{\bullet \bullet}+\mathrm{CaO} \\
2 \mathrm{Y}_{\mathrm{Y}}+3 \mathrm{O}_{\mathrm{O}} \rightarrow 2 \mathrm{~V}_{\mathrm{Y}}^{\prime \prime \prime}+3 \mathrm{~V}_{\mathrm{O}}^{\bullet \bullet}+\mathrm{Y}_{2} \mathrm{O}_{3} \\
2 \mathrm{Al}_{\mathrm{Al}}+3 \mathrm{O}_{\mathrm{O}} \rightarrow 2 \mathrm{~V}_{\mathrm{Al}}^{\prime \prime \prime}+3 \mathrm{~V}^{\bullet \bullet}+\mathrm{Al}_{2} \mathrm{O}_{3} \\
\mathrm{Ca}_{\mathrm{Ca}}+2 \mathrm{Al}_{\mathrm{Al}}+4 \mathrm{O}_{\mathrm{O}} \rightarrow \mathrm{V}_{\mathrm{Ca}}^{\prime \prime}+2 \mathrm{~V}_{\mathrm{Al}}^{\prime \prime \prime}+4 \mathrm{~V}_{\mathrm{O}}^{\bullet \bullet}+\mathrm{CaAl}_{2} \mathrm{O}_{4} \\
\mathrm{Y}_{\mathrm{Y}}+\mathrm{Al}_{\mathrm{Al}}+3 \mathrm{O}_{\mathrm{O}} \rightarrow \mathrm{V}_{\mathrm{Y}}^{\prime \prime \prime}+\mathrm{V}_{\mathrm{Al}}^{\prime \prime \prime}+3 \mathrm{~V}_{\bullet}^{\bullet \bullet}+\mathrm{YAlO}_{3} \\
\mathrm{Ca}_{\mathrm{Ca}}+\mathrm{Y}_{\mathrm{Y}}+\mathrm{Al}_{\mathrm{Al}}+4 \mathrm{O}_{\mathrm{O}} \rightarrow \mathrm{V}_{\mathrm{Ca}}^{\prime \prime}+\mathrm{V}_{\mathrm{Y}}^{\prime \prime \prime}+\mathrm{V}_{\mathrm{Al}}^{\prime \prime \prime}+4 \mathrm{~V}_{\mathrm{O}}^{\bullet \bullet}+\mathrm{CaYAlO}_{4}\end{array}$ \\
\hline $\begin{array}{l}\text { Schottky } \\
\end{array}$ \\
\hline$\overline{\mathrm{Ca}_{\mathrm{Ca}}+\mathrm{Y}_{\mathrm{Y}}+3 \mathrm{Al}_{\mathrm{Al}}+7 \mathrm{O}_{\mathrm{O}} \rightarrow \mathrm{V}_{\mathrm{Ca}}^{\prime \prime}+\mathrm{V}_{\mathrm{Y}}^{\prime \prime \prime}+3 \mathrm{~V}_{\mathrm{Al}}^{\prime \prime \prime}+7 \mathrm{~V}_{\mathrm{O}}^{\bullet \bullet}+\mathrm{CaYAl}_{3} \mathrm{O}_{7}}$ \\
\hline anti-Schottky \\
\hline
\end{tabular}

Table $\mathrm{V}$ shows a comparison of formation energies of basic defects in CYAM calculated by the supercell method compared with those calculated using the MottLittleton methodology, assuming no defect binding. The essential difference between both methods is in defect
Solution energies for intrinsic defects.

TABLE V

\begin{tabular}{|c|c|c|c|}
\hline \multirow{2}{*}{$\begin{array}{c}\text { Defect } \\
\text { type }\end{array}$} & ML & \multicolumn{2}{|c|}{$\mathrm{SC}$} \\
\hline & \multicolumn{2}{|c|}{ Energy $[\mathrm{eV} /$ defect] } & No. of config. \\
\hline \multicolumn{4}{|c|}{ Frenkel } \\
\hline $\mathrm{Y}$ & 7.56 & $3.23 \pm 0.61$ & 5994 \\
\hline $\mathrm{Ca}$ & 4.34 & $2.75 \pm 0.43$ & 5994 \\
\hline $\mathrm{Al}$ & 8.31 & $4.77 \pm 0.64$ & 8103 \\
\hline $\mathrm{O}$ & 3.63 & $2.24 \pm 0.21$ & 38625 \\
\hline \multicolumn{4}{|c|}{ Pseudo-Schottky } \\
\hline $\mathrm{CaO}$ & 4.90 & $3.01 \pm 0.17$ & 20250 \\
\hline $\mathrm{Y}_{2} \mathrm{O}_{3}$ & 6.00 & $3.44 \pm 0.14$ & 20250 \\
\hline $\mathrm{Al}_{2} \mathrm{O}_{3}$ & 5.93 & $3.74 \pm 0.15$ & 61125 \\
\hline $\mathrm{CaAl}_{2} \mathrm{O}_{3}$ & 4.24 & $3.44 \pm 0.14$ & 3300750 \\
\hline $\mathrm{YAlO}_{3}$ & 6.00 & $3.39 \pm 0.14$ & 3300750 \\
\hline $\mathrm{CaYAlO}_{4}$ & 6.01 & $3.68 \pm 0.01$ & 178220625 \\
\hline \multicolumn{4}{|c|}{ Schottky } \\
\hline & 5.70 & $3.44 \pm 0.14$ & 178096617 \\
\hline \multicolumn{4}{|c|}{ anti-Schottky } \\
\hline & 4.67 & $2.66 \pm 0.18$ & 139952421 \\
\hline
\end{tabular}

concentration where the Mott-Littleton method is at the dilute limit $[14,16]$, but in the supercell method a concentration of defects beyond the dilute limit can be established. The concentration of defects can be controlled by varying the size of the supercell and/or the number of defects within it, therefore, an increase of size reduces concentration and the predicted formation energy obtained from the supercell method converges toward the MottLittleton result $[14,17]$. Results are quantitatively different, with formation energies from the supercell method being approximately double the Mott-Littleton method, but qualitatively they give the same result with the $\mathrm{O}$ Frenkel being the most favourable defect.

The energies from the supercell method were obtained by averaging over all possible combinations of defects in the supercell.

\section{Conclusions}

Supercells with $\mathrm{Ca} / \mathrm{Y}$ ions distributed randomly, keeping the composition ratio of $1: 1$, were built to reproduce the standard XRD patterns of CYAM. A $3 \times 3 \times 3$ supercell was chosen as this gives the best overall agreement. A set of potential parameters were obtained by empirical fitting that reproduce the CYAM and precursor oxides crystal structures to within $1.09 \%$ and $3.09 \%$, respectively. The intrinsic defect formation energies were calculated using supercell and the Mott-Littleton methods. Both methods predict oxygen Frenkel defects are most likely to be formed.

\section{References}

[1] H. Zhang, C.-N. Xu, N. Terasaki, H. Yamada, Electrochem. Solid-State Lett. 14, J76 (2011).

[2] N. Kodama, Y. Tanii, M. Yamaga, J. Lumin. 87-89, 1076 (2000).

[3] V. Singh, V.K. Rai, K. Al-Shamery, J. Nordmann, M. Haase, J. Lumin. 131, 2679 (2011). 
[4] H. Zhang, H. Yamada, N. Terasaki, C.-N. Xu, J. Electrochem. Soc. 155, J128 (2008).

[5] S. Unithrattil, K.H. Lee, W.J. Chung, W. Bin Im, J. Lumin. 152, 176 (2014).

[6] H. Xiumei, Y. Xin, Q. Jianquan, Q. Xiwei, W. Xiaoqiang, L. Mingya, S. Xudong, W. Chen, J. Nanosci. Nanotechnol. 16, 730 (2016).

[7] V. Singh, S. Watanabe, T.K.G. Rao, H.-Y. Kwak, J. Fluoresc. 21, 313 (2011).

[8] P. Dessovic, P. Mohn, R.A. Jackson, G. Winkler, M. Schreitl, G. Kazakov, T. Schumm, J. Phys. Condens. Matter 26, 105402 (2014).

[9] M.V.S. Rezende, D.J. Santos, R.A. Jackson, M.E.G. Valerio, Z.S. Macedo, J. Solid State Chem. 238, 210 (2016).

[10] J.B. Amaral, M.A. Couto dos Santos, M.E.G. Valerio, R.A. Jackson, Appl. Phys. B 81, 841 (2005).
[11] A.C. Larson, R.B. Von Dreele, General Structure Analysis System (GSAS), Los Alamos National Laboratory Report LAUR 86-748, 1994.

[12] G.M. Kuz'micheva, B.V. Mukhin, V.B. Rybakov, A.L. Denisov, E.V. Zharikov, V.A. Smirnov, Zh. Neorg. Khim. 40, 562 (1995).

[13] J.D. Gale, JCS Faraday Trans. 93, 629 (1997).

[14] R.A. Jackson, J.E. Huntington, R.G.J. Ball, J. Mater. Chem. 1, 1079 (1991).

[15] N.F. Mott, M.J. Littleton, Trans. Faraday Soc. 34, 485 (1938).

[16] M.V. dos S. Rezende, M.E.G. Valerio, R.A. Jackson, Opt. Mater. 34, 109 (2011).

[17] S.T. Murphy, H. Lu, R.W. Grimes, J. Phys. Chem. Solids 71, 735 (2010). 